\title{
The Role of Learning Organization Dimensions on Enhancing Knowledge Creation: The Case of Commercial Banks Working in Jordan
}

\author{
Nadera Hourani ${ }^{1}$ \\ ${ }^{1}$ Faculty of Human Resource Management, King Abdul-Aziz University, The Kingdom of Saudi Arabia \\ Correspondence: Dr. Nadera Hourani, Faculty of Human Resource Management, King Abdul-Aziz University, \\ The Kingdom of Saudi Arabia. E-mail: nadra_hourani@yahoo.com
}

Received: March 6, 2019

Accepted: September 10, 2019

Online Published: October 14, 2019

doi:10.5539/ijbm.v14n11p153

URL: https://doi.org/10.5539/ijbm.v14n11p153

\begin{abstract}
:
Nowadays, through the competitive business, creativity and innovation are essential elements that lead organizations to generate concepts of value, worth and be in the racetrack of worldwide competition. There was an urgent need to emerge new concepts that strengthen and fasten the speed of developing business. Important concepts are Learning Organization and Knowledge Creation, both together ensure acquiring life skills and professional stability and security through facilitating the learning process. The current study tries to seek answers that identify and explore the role of learning organization dimensions on enhancing knowledge creation. The sample consisted of all executives working in (10) commercial banks operating in Jordan featuring (134) individuals. The study found that learning organization dimensions have impact on enhancing knowledge creation. Thus, commercial banks seek to improve the team dynamics, build their skills and experiences, and builds a high performing team which reflects on the positively on the banks, and helping them to continue running effectively. The findings suggest further research must be considered about other units of analysis.
\end{abstract}

Keywords: learning organization, knowledge creation, commercial banks, Jordan

\section{Introduction}

Recently, new concepts have emerged due to the need of strengthening and fastening the speed of developing business. One important concept is learning organization that defines a perspective in which SME, huge companies and firms use to facilitate the learning process and reshaping the experiences of their working members (Ghaffari, Burgoyne, \& Shah, 2017). In addition to, it explains the processes and practices that encourage learning in organisations and to create ongoing learning opportunities (Vince, 2018). Such perspective empowers teams to have better potential and be capable of developing their creativity to accomplish more and perform better to reach the levels of satisfaction their employers expect (Dekoulou \& Trivellas, 2015; Örtenblad, 2018).

Organizations seek always the effective use of new knowledge and being able to develop new capabilities. Therefore, output or the final products of the knowledge created is not only organizational practices but managerial systems and new methods that characterize the knowledge about customers through knowing and exploring their needs and attitudes (Hislop et al., 2018). According to Grimsdottir and Edvardsson (2018) the initial starting point of knowledge management is Knowledge creation. Massaro et al. (2016) adds that Knowledge creation has a crucial impact on in developing and enhancing innovation. Therefore, knowledge creation and innovative organizations are quite interconnected; in other words, organization can be classified or seen as creative whenever it is able to create new knowledge and practices at the working environment (Jarvenpaa \& Tanriverdi, 2018). The impact of creating new knowledge can be seen through organizations being able to improve internal management aspect new production that is concentrated mainly on customers' needs and preferences (Massaro et al., 2016).

In Jordan, banking sector is considered one of the most important and dynamic sectors that develops economy of the country as empowers it to have great potential and impact in the international market. In addition to, it represents an essential pillar that activates various sectors. Banking sector depends very much through achieving incomes on arranging priorities and techniques to reach the long-term goals (Hassan, Iqbal, \& Ghias, 2017). 
Therefore, knowledge management is important in enhancing and achieving competitive advantages (Hajir, et al, 2015) that is distinctive in order to target innovation, learning, and performance that emphasis and intensify development (Martineau, Knox, \& Combs, 2014; Arijitsatien \& Ractham, 2017).

The current study stems its distinguished aspects of being unique as there is a lack of studies and research that tackle the impact of learning organization dimensions on enhancing knowledge creation. Hence, applying the concept of learning organization enables banks to acquire information and comprehension through examination, investigation, and analysis in order to be prepared to all risks. This leads in turn to reduce and prevent eventually failure, and bring opportunities to be more organized. Unlike other research, the current study seeks answers that identify and explore the role of learning organization dimensions on enhancing knowledge creation. Thus, the researcher has generated the following hypotheses;

\section{Hypothesis}

1. Main Hypothesis (H01). There is no statistically significant of the role of learning organization dimensions on enhancing knowledge creation at the level $(\alpha \leq 0.05)$.

This hypothesis is divided into three sub-hypotheses:

- H01-1: There is no statistically significant impact of learning organization dimensions (Team learning، System connection، Continuous learning) on the socialization at level $(\alpha \leq 0.05)$.

- H01-2: There is no statistically significant impact of learning organization dimensions (Team learning، System connection، Continuous learning) on the externalization at level $(\alpha \leq 0.05)$.

- H01-3: There is no statistically significant impact of learning organization dimensions (Team learning, System connection, Continuous learning) on the internalization at level $(\alpha \leq 0.05)$.

- H01-4: There is no statistically significant impact of learning organization dimensions (Team learning, System connection, Continuous learning) on the combination at level $(\alpha \leq 0.05)$.

The current study shades the light on commercial banks working in Jordan. The researcher hopes to suggests insights that enrich the future research in this filed

\section{Learning Organization}

Conceptually, learning organization is described as an organization that facilitates the learning process and gaining experiences for all its members (Baldwin, 2016). Where it constantly changes and develops itself in order to achieve its strategic goals to become a learning unit in itself. Therefore, employees acquire skills and experiences in the workplace in an informal way instead of attending out-office learning methods (Ghaffari, Burgoyne \& Shah, 2017). Organizations that follow such approach are capable of developing their teams' creativity to accomplish all the tasks required in high efficiency in order to reach the expected results and performance.

Learning organization approach aims to increase the well-being of the employees and motivate them to enhance performance (Örtenblad, 2018). Thus, it increases their competitive ability and performance, which reflect positively on achieving the objectives of organization and raise its efficiency. Moreover, it provides the knowledge to deal with emergencies that may occur at work in order to enhance employee's affiliation to the workplace and consciousness. In this context, McKenzie et. Al (2018) add further that the more employees feel comfortable and satisfied with their performance at work, the more self-confident, productive and effective became in achieving professional advancement especially middle managers. Such approach ensures acquiring life skills and professional stability and security.

Learning organization - as approach- supports the employees to expand the ability to to think creatively and improve their points of strength (Bryson, 2018). To apply that, organizations tend to involve employees in decision-making process and evaluating the workflow. This has been considered a great factor in increasing the production and the competitiveness (Nazari \& Pihie, 2012). Therefore, learning organization relays on important dimensions that make such a goal achievable. The current study focuses on three main dimensions;

A. Team Learning: which refers to the use of the training methods within the team in order to urge the employees to cooperate and work within the team spirit (Watkins, 2018). In addition, the team learning stimulates them to help each other to overcome any problem that may disrupt the workflow. Consequently, this reflects positively on the public interest, vision and objectives of the organization (Song, Joo, \& Chermack, 2009). 
B. Inquiry and Dialogue: employees learn the correct mechanism and methods to ask effectively the right questions. This allows them to express their opinion and listen to others in order to gain the skill of logical thinking according to Hussein, Mohamad, Noordin \& Ishak (2014). Also, this dimension provides the mechanisms of effective dialogue between them and directors to be more involved in the decision-making process (Leufvén, Vitrakoti, Bergström, Ashish, \& Målqvist,2015).

C. Continuous Learning: this refers to acquiring new skills to help employees at the workplace and personal life (Hallam,Hiskens,\& Ong,2015). Thus, employees can deal with all the changes in the work mechanisms and the new challenges that he may occur in the workplace (Dekoulou \& Trivellas, 2015).

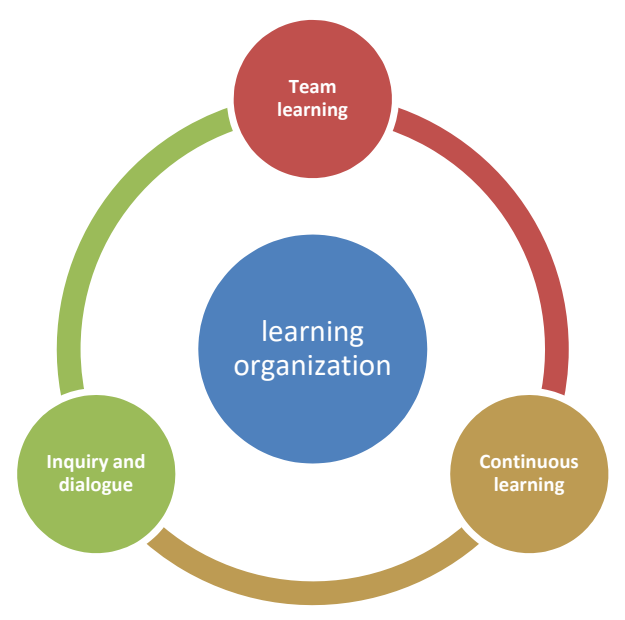

Figure 1: Learning organization's dimensions

Source: Leufvén,Vitrakoti, Bergström, Ashish, and Målqvist (2015).

\subsection{Knowledge Creation}

Knowledge creation is a new direction in knowledge management that is emerging from creativity and innovation (Yang, Fang, \& Lin, 2010). Nowadays, through the competitive business, creativity and innovation are essential elements that lead organizations to generate concepts of value, worth and be in the racetrack of worldwide competition (Hong, 2010). In this context, knowledge management is extremely confirmed on spreading knowledge in order to obtain competitive advantage. Therefore, creativity or innovation is needed to generate new kinds of products, technologies, as well as managerial systems (Tan, 2014). Hence, knowledge management is vital to promote and develop the creation of knowledge in organizations in order to earn value, worth and achieve high quality of performance and efficiency (Pei, 2008; Räisänen, 2010).

The creation of effective knowledge has been described as a process of self-transcendence, in which older methods and techniques go beyond new approaches through which new contexts and perspectives are acquired outside and within the organization (Akhavan, Ghojavand, \& Abdali, 2012). It also can be defined as the company's ability to generate new knowledge and spread it in different parts of the organization then present it through system, products, and services (Harris, 2009). Therefore, knowledge creation is an essential and important factor in enhancing and developing the performance of organizations, as well it contributes to improve the intellectual capabilities in order to create new knowledge that leads to increase the growth of competitive advantage throughout the organization (Nadayama, 2010).

Knowledge creation is derived from two dimensions; the first dimension demonstrates individuals, who can create knowledge, and the second shows the integration of explicit and tacit knowledge (Naicker, Govender, \& Naidoo, 2014). These two dimensions shape the ground foundation for defining the processes of knowledge creation. Those processes are:

A. Socialization: this process refers to sharing tacit knowledge. In other words, to make experience as an open-book shared between the team, through brain storming, conferences, apprenticeships, and making suggestions (Chatterjee et al., 2018). 
B. Externalization: it's the process of transferring tacit knowledge to explicit knowledge, through the knowledge that has been shared through metaphors, figures, and ideas (Sánchez, Sánchez, Collado-Ruiz, Cebrián-Tarrasón, 2013).

C. Combination: it's the process of combining different kinds of tacit knowledge and explicit knowledge. Hence, collecting explicit knowledge can happen in or out of the organization, then it can be shaped or edited to be processed into a new form.

D. Internalization: this represent applying the principal of learning by doing, though, absorbing explicit knowledge to become within individual's knowledge (Chatterjee et . al, 2018).

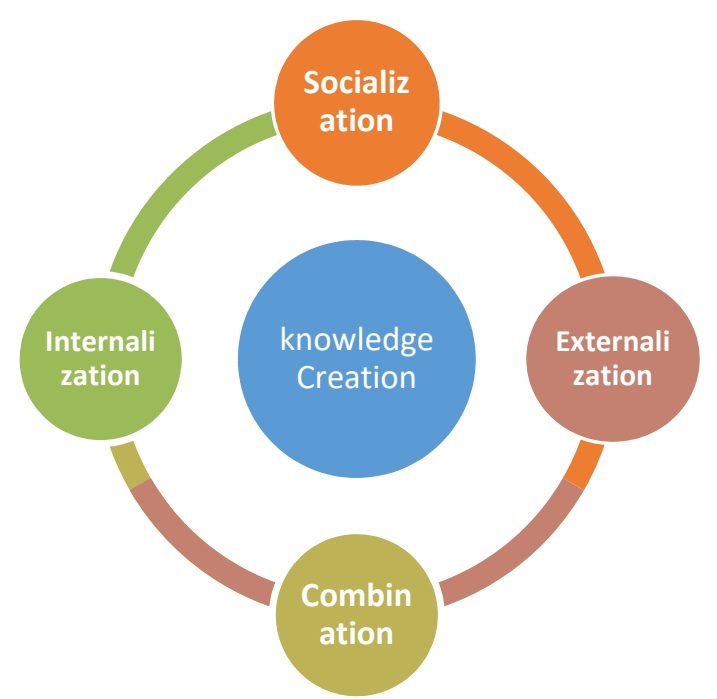

Figure 2. Knowledge creation processes

Source: Niccolini, Bartolacci, Cristalli, and Isidori (2018).

\section{Research Methodology}

\subsection{Population and Sampling}

The current study population consists of all executives in (25) commercial banks operating in Jordan. Meanwhile, The study sample consists of all executives in (10) banks working in Jordan. The number of executives consisted of (134) individuals, illustrated in the table below:

Table 1. Sample description

\begin{tabular}{lll}
\hline & Banks name & Number of Executives \\
\hline 1 & Bank of Jordan & 13 \\
2 & Jordan Kuwait Bank & 15 \\
3 & Investment Bank & 13 \\
4 & Jordan Commercial Bank & 13 \\
5 & Union Bank & 15 \\
6 & Arab Investment Bank & 12 \\
7 & Bank Audi & 13 \\
8 & Blom Bank Blom Bank & 12 \\
9 & Housing Bank & 14 \\
10 & Capital Bank & 14 \\
Total & 134 \\
\hline
\end{tabular}




\subsection{Instrument Design}

A questionnaire consisted of (21) items measuring learning organization dimensions on enhancing knowledge creation has been used to collect data. The researcher tended to collect data by distributed the questionnaire by hand on the sample. The questionnaire is designed to include: demographic variables, learning organization dimensions (team learning, inquiry and dialogue, continuous learning), and knowledge creation (socialization, combination, internalization and externalization).

\subsection{Instrument Validity}

Based on 5-point Likert scale, respondents were asked to read each item, and select a choice that represents their attitude, in which score 5 represents (strongly agree), score 4 represents (agree), score represent a (neutral) attitude, score 2 represents a (disagree) attitude and score 1 represent a (strongly disagree) attitude. To ensure the instrument validity, the researcher has relied on Cronbach's alpha test to insure the stability of the results as illustrated in table 2 below:

Table 2. Cronbach's alpha for the study fields

\begin{tabular}{lll}
\hline $\begin{array}{l}\text { Field } \\
\text { Number }\end{array}$ & Field & Value of $(\boldsymbol{\alpha})$ \\
\hline \multicolumn{2}{l}{ Learning } & Organization \\
$\mathbf{1}$ & Team Learning & $\mathbf{0 . 8 8 3}$ \\
$\mathbf{2}$ & Inquiry and Dialogue & $\mathbf{0 . 8 6 8}$ \\
$\mathbf{3}$ & Continuous Learning & $\mathbf{0 . 9 0 7}$ \\
Knowledge & Creation \\
$\mathbf{1}$ & Socialization & $\mathbf{0 . 8 7 5}$ \\
$\mathbf{2}$ & Combination & $\mathbf{0 . 8 3 0}$ \\
$\mathbf{3}$ & Internalization & $\mathbf{0 . 8 5 4}$ \\
$\mathbf{4}$ & Externalization & $\mathbf{0 . 8 5 8}$ \\
\hline
\end{tabular}

As shown from the table 2 that the total Cronbach's alpha for the study fields was above than $(0.60)$ which will leads to the stability of the results for this study.

\section{Data Analysis and Interpretation}

To examine the study hypotheses, Statistical Package for Social Sciences (SPSS) is used to process the collected data. The following statistical techniques were needed:

1) Descriptive Statistical Techniques: including; means and standard deviations. These techniques were used to illustrate respondents to study fields.

2) Reliability Test: to check the reliability of the instruments and highlight the stability of consistency of instrument.

3) Frequencies and Percentages: to describe demographical variables.

4) Normality Tests.

5) Multiple Regression Test: to explore the direct impacts of variables.

\subsection{Descriptive Statistics}

\subsubsection{Demographic Characteristics}

The tables describe the participants demographically. The variables are (gender, academic level, and years of experience).

Table 3. Demographic characteristics based on gender

\begin{tabular}{lll}
\hline Gender & Sample & \\
& Frequency & Percentage \\
\hline Male & 68 & $50.7 \%$ \\
Female & 66 & $49.3 \%$ \\
Total & 134 & $100 \%$ \\
\hline
\end{tabular}


From the table 3 it shows that $(50.7 \%)$ of participants were men, meanwhile $(49.3 \%)$ were women.

Table 4. Demographic characteristics based on academic level

\begin{tabular}{lll}
\hline Academic Level & Sample \\
\cline { 2 - 3 } & Frequency & Percentage \% \\
\hline Bachelor (B.A) & 23 & $17.2 \%$ \\
Master (M.A) & 104 & $77.6 \%$ \\
Doctoral (PhD) & 7 & $5.2 \%$ \\
Total & 134 & $100.0 \%$ \\
\hline
\end{tabular}

For the variable (Academic Level), (17.2\%) of the participants hold B.A., (77.6 \%) hold M.A.s. Meanwhile, $(5.2 \%)$ of the overall participants hold $\mathrm{PhD}$.

Table 5. Demographic characteristics based on years of experience

\begin{tabular}{lll}
\hline Years of Experience & Sample & \\
& Frequency & Percentage \% \\
\hline 1-3years & 52 & $38.8 \%$ \\
More than 3-5 years & 56 & $41.8 \%$ \\
More than 5 years & 26 & $19.4 \%$ \\
Total & 134 & $100.0 \%$ \\
\hline
\end{tabular}

\subsection{Means and Standard Deviation}

Means and standard deviation were calculated for each field in the study instrument and Table 6 shows the results.

Table 6. Descriptive Statistics for the Role of Learning Organization on Enhancing Knowledge Creation

\begin{tabular}{lllll}
\hline $\begin{array}{l}\text { field } \\
\text { number }\end{array}$ & Field & Mean & Std. Deviation & Level \\
\hline F1 & Team learning & 2.59 & 0.75 & Medium \\
F2 & Inquiry and dialogue & 2.59 & 0.75 & Medium \\
F3 & Continuous learning & 2.57 & 0.78 & Medium \\
F4 & Socialization & 2.48 & 0.74 & Medium \\
F5 & Combination & 2.45 & 0.71 & Medium \\
F6 & Internalization & 2.51 & 0.73 & Medium \\
F7 & Externalization & 2.55 & 0.75 & Medium \\
\hline
\end{tabular}

As it seen above, when it comes to role of learning organization, the means were somehow close in which: Team learning field achieved mean reached (2.59) with standard deviation of (0.75), Inquiry and dialogue field achieved mean reached (2.59) with standard deviation of (0.75), and Continuous learning achieved mean reached (2.57), with standard deviation (0.78). Meanwhile, when it comes to Knowledge Creation processes, there was a tiny variation in the means, in which Socialization achieved mean reached $(2.48)$, = with standard deviation of (0.74), Combination achieved mean reached (2.45), with standard deviation of (0.71), Internalization achieved mean reached (2.51), with standard deviation of (0.73). and Externalization achieved mean reached (2.55), and a standard deviation (0.75).

\subsection{Hypotheses}

Main Hypothesis (H01). There is no statistically significant of the role of learning organization dimensions on enhancing knowledge creation at the level $(\alpha \leq 0.05)$.

To check validity of multiple regression for this model VIF and tolerance were calculated for each field for independent variables as the following table. 
Table 7. VIF and tolerance for each field for independent variables

\begin{tabular}{lll}
\hline Field & Tolerance & VIF \\
\hline Team learning & .397 & 2.517 \\
Inquiry and dialogue & .466 & 2.145 \\
Continuous learning & .512 & 1.954 \\
\hline
\end{tabular}

As shown in the table 7, VIF values are (less than 10) which leads to the compatibility of using regression test. However, regression modelling to test the hypothesis can be used for those values that are more than (0.05).

We used Multiple Regression test to check the direct impact of learning organization on enhancing knowledge creation shown in the table 8 .

Table 8. Multiple Regression test to check the direct impact of learning organization dimensions on enhancing knowledge creation

\begin{tabular}{|c|c|c|c|c|c|c|c|c|c|}
\hline \multirow[t]{2}{*}{ Dependent Variable } & \multirow[t]{2}{*}{$\mathrm{R}$} & \multirow[t]{2}{*}{$\mathrm{R}^{2}$} & \multirow[t]{2}{*}{$\mathrm{F}$} & \multirow[t]{2}{*}{ Sig } & \multirow[t]{2}{*}{$\mathrm{DF}$} & \multicolumn{4}{|l|}{ Coefficients } \\
\hline & & & & & & Predictor & B & $\mathrm{T}$ & Sig \\
\hline \multirow{5}{*}{ knowledge creation } & .871 & .759 & 136.251 & .000 & 3 & Constant & .339 & 3.048 & .003 \\
\hline & & & & & & Team learning & .151 & 2.568 & .011 \\
\hline & & & & & 130 & & & & \\
\hline & & & & & & Inquiry and dialogue & .307 & 5.665 & .000 \\
\hline & & & & & 133 & Continuous learning & .378 & 7.549 & .000 \\
\hline
\end{tabular}

The table above shows that there is significant effect for learning organization dimensions on enhancing knowledge creation. This is due to the significant value that was (0.000) which is less than (0.05).The value of $R$ is the square root of R-Squared and is the correlation between the observed and predicted values of dependent variable was (0.871). As well, the coefficient of determination R2 (0.759). Moreover, about $75.9 \%$ of the variation in changing knowledge creation explained by learning organization. Restriction Parameter (F) was (136.251) of the learning organization on enhancing knowledge creation. Thus, we will accept the alternative the hypotheses "There is statistically significant of the role of learning organization dimensions on enhancing knowledge creation at the level $(\alpha \leq 0.05)$.

- Ho1-1: There is no statistically significant impact of learning organization dimensions (Team learning 'System connection' Continuous learning) on the socialization at level $(\alpha \leq 0.05)$

We used Multiple Regression test to check the direct impact of learning organization dimensions on Socialization, table 9 illustrates that:

Table 9. Multiple Regression test to check the direct impact of learning organization dimensions on Socialization

\begin{tabular}{|c|c|c|c|c|c|c|c|c|c|}
\hline Dependent Variable & $\mathbf{R}$ & $\mathbf{R}^{2}$ & $\mathbf{F}$ & Sig & DF & $\begin{array}{l}\text { Coefficients } \\
\text { Predictor }\end{array}$ & B & $\mathbf{T}$ & Sig \\
\hline \multirow{5}{*}{ Socialization } & \multirow{5}{*}{.748} & \multirow{5}{*}{.559} & \multirow{5}{*}{54.393} & \multirow{5}{*}{.000} & \multirow{2}{*}{3} & Constant & .431 & 2.518 & .013 \\
\hline & & & & & & Team learning & .354 & 3.906 & .000 \\
\hline & & & & & 130 & & & & \\
\hline & & & & & 130 & Inquiry and dialogue & .030 & .357 & .722 \\
\hline & & & & & 133 & Continuous learning & .409 & 5.296 & .000 \\
\hline
\end{tabular}

As it shown above, there is significant effect for learning organization on socialization; the significant value was (0.000) less than (0.05), the value of $\mathrm{R}$ is the square root of R-Squared and is the correlation between the observed and predicted values of dependent variable was $(0.748)$, the coefficient of determination R2 (0.559). Therefore, about $55.9 \%$ of the variation in changing socialization explained by learning organization. Restriction Parameter (F) was (54.393) of the learning organization on socialization, and thus we will accept the alternative the hypotheses "There is statistically significant of learning organization dimensions (Team learning، System connection، Continuous learning) on the Socialization at level $(\alpha \leq 0.05)$. 
- Ho1-2: There is no statistically significant impact of learning organization dimensions (Team learning، System connection، Continuous learning) on the externalization at level $(\alpha \leq 0.05)$

We used Multiple Regression test to check the direct impact of learning organization dimensions on externalization shown in the table 10.

Table 10. Multiple Regression test to check the direct impact of learning organization dimensions on externalization

\begin{tabular}{|c|c|c|c|c|c|c|c|c|c|}
\hline \multirow{2}{*}{ Dependent Variable } & \multirow{2}{*}{$\mathbf{R}$} & \multirow{2}{*}{$\mathbf{R}^{2}$} & \multirow[t]{2}{*}{$\mathbf{F}$} & \multirow{2}{*}{ Sig } & \multirow{2}{*}{ DF } & \multicolumn{4}{|l|}{ Coefficients } \\
\hline & & & & & & Predictor & B & $\mathbf{T}$ & Sig \\
\hline \multirow{5}{*}{ externalization } & \multirow{5}{*}{.826} & \multirow{5}{*}{.683} & \multirow{5}{*}{93.258} & \multirow{5}{*}{.000} & \multirow{2}{*}{3} & Constant & .182 & 1.297 & .197 \\
\hline & & & & & & Team learning & .189 & 2.543 & .012 \\
\hline & & & & & & & & & \\
\hline & & & & & 130 & Inquiry and dialogue & .322 & 4.698 & .000 \\
\hline & & & & & 133 & Continuous learning & .367 & 5.784 & .000 \\
\hline
\end{tabular}

As it shown above, there is significant effect for learning organization on externalization; the significant value was $(0.000)$ less than $(0.05)$, the value of $\mathrm{R}$ is the square root of R-Squared and is the correlation between the observed and predicted values of dependent variable was (0.826), and the coefficient of determination R2 (0.683). Therefore, about $68.3 \%$ of the variation in changing externalization explained by learning organization. Restriction Parameter (F) was (93.258) of the learning organization on externalization. Thus, we will accept the alternative the hypotheses "There is statistically significant of learning organization dimensions (Team learning، System connection، Continuous learning) on the externalization at level $(\alpha \leq 0.05)$.

- Ho1-3: There is no statistically significant impact of learning organization dimensions (Team learning، System connection، Continuous learning) on the internalization at level $(\alpha \leq 0.05)$

We used Multiple Regression test to check the direct impact of learning organization on internalization shown in the table 11 .

Table 11. Multiple Regression test to check the direct impact of learning organization dimensions on internalization

\begin{tabular}{|c|c|c|c|c|c|c|c|c|c|}
\hline Dependent Variable & $\mathbf{R}$ & $\mathbf{R}^{2}$ & $\mathbf{F}$ & Sig & DF & $\begin{array}{l}\text { Coefficients } \\
\text { Predictor }\end{array}$ & B & $\mathbf{T}$ & Sig \\
\hline \multirow{5}{*}{ Internalization } & \multirow{5}{*}{.789} & \multirow{5}{*}{.622} & \multirow{5}{*}{71.266} & \multirow{5}{*}{.000} & \multirow{2}{*}{3} & Constant & .339 & 2.165 & .032 \\
\hline & & & & & & Team learning & .021 & .258 & .797 \\
\hline & & & & & \multirow{2}{*}{130} & & & & \\
\hline & & & & & & Inquiry and dialogue & .424 & 5.548 & .000 \\
\hline & & & & & 133 & Continuous learning & .396 & 5.614 & .000 \\
\hline
\end{tabular}

As it shown above, there is significant effect for learning organization on internalization. This due to significant value as it is (0.000) that is less than (0.05), the value of $\mathrm{R}$ is the square root of R-Squared and is the correlation between the observed and predicted values of dependent variable was $(0.789)$ and the coefficient of determination R2 (0.622). Therefore, about $62.2 \%$ of the variation in changing internalization explained by learning organization. Restriction Parameter (F) was (71.266) of the learning organization on internalization, and thus we will accept the alternative the hypotheses "There is statistically significant of learning organization dimensions with its dimensions (Team learning، System connection، Continuous learning) on the internalization at level $(\alpha \leq 0.05)$.

- Ho1-4: There is no statistically significant impact of learning organization dimensions (Team learning، System connection، Continuous learning) on the combination at level $(\alpha \leq 0.05)$

We used Multiple Regression test to check the direct impact of learning organization on combination shown in the table 12 . 
Table 12. Multiple Regression test to check the direct impact of learning organization dimensions on combination

\begin{tabular}{|c|c|c|c|c|c|c|c|c|c|}
\hline Dependent Variable & $\mathbf{R}$ & $\mathbf{R}^{2}$ & $\mathbf{F}$ & Sig & DF & $\begin{array}{l}\text { Coefficients } \\
\text { Predictor }\end{array}$ & B & $\mathbf{T}$ & Sig \\
\hline \multirow{5}{*}{ Combination } & \multirow{5}{*}{.758} & \multirow{5}{*}{.575} & \multirow{5}{*}{58.544} & \multirow{5}{*}{.000} & \multirow{2}{*}{3} & Constant & .402 & 2.359 & .020 \\
\hline & & & & & & Team learning & .040 & .439 & .662 \\
\hline & & & & & \multirow{2}{*}{130} & & & & \\
\hline & & & & & & Inquiry and dialogue & .452 & 5.438 & .000 \\
\hline & & & & & 133 & Continuous learning & .341 & 4.435 & .000 \\
\hline
\end{tabular}

As it shown from the table above, there is significant effect for learning organization on combination because the significant value was (0.000) less than $(0.05)$, the value of $\mathrm{R}$ is the square root of $\mathrm{R}$-Squared and is the correlation between the observed and predicted values of dependent variable was $(0.758)$ and the coefficient of determination R2 (0.575). Therefore, about $57.5 \%$ of the variation in changing combination explained by learning organization. Restriction Parameter (F) was (58.544) of the learning organization on combination, and thus we will accept the alternative the hypotheses "There is statistically significant of learning organization dimensions (Team learning، System connection، Continuous learning) on the combination at level $(\alpha \leq 0.05)$.

\section{Discussion and Conclusion}

\subsection{Discussion}

Responding to (Donate \& de Pablo (2015) that assured the importance of conducting more research that tackles learning organization, knowledge management and practices through enhancing knowledge creation processes. The study has made a conceptual case that shows the role in which learning organization plays on enhancing knowledge focusing on the commercial banks working in Amman. The results of the means and standard deviations of the role of learning organization on enhancing knowledge creation. This indicates that commercial banks seek to improve team's dynamics, build their skills through rich experiences. Consequently, this builds a high performing team which reflects positively on the banks to continue running effectively. It also may indicates that banks keen to develop teamwork in order to provide an excellent performance, which enables banks to provide a high quality of the services.

Testing The main hypothesis (H01), confirms a statistically significant of the role of learning organization on enhancing knowledge creation. This indicates that learning organization in banks create opportunities to deal with environmental change and uncertainties and a sustainable competitive advantage. It also unites the Bank's long-term shared vision. Moreover, such a result might indicate that organizational learning is an ongoing effort exerted by the bank in building and improving knowledge creation in methods that assure reaching common meanings that can be used to solve the problems faced by different administrative levels.

Interestingly, Socialization as is highly associated with learning organization in which the last affects positively the process of sharing tacit knowledge. . This is can be interpreted as banks rely on developing the employee improving their skills, and sharing experiences in order to create implicit knowledge such as mental models and common technical skills. Another point the study has confirmed that there is statistically significant of learning organization on the externalization. This the researcher has interpreted that as banks seek to encourage the executives and employees to share knowledge, experiences, skills and practices among team members within the bank in order to create high knowledge productivity, and build new service ideas. Thus, Banks gain competitive advantage and generate high profitability returns. Moreover, learning organization affects positively on internalization. This indicates that banks seek to provide training programs, simulations, experiments, and use of documents on work assignments and job rotation in order to influence the efficiency of organizational processes, and achieve rapid response to market changes. Finally, there is statistically significant of learning organization on the combination. Banks urge executives and employees to communicate among groups, disseminate, and circulate knowledge within the bank through meetings, telephone conversations or communication networks in order to help them to share ideas and experiences, which enable banks to achieve an increase in profits and returns, and then raise the competitive side.

\subsection{Research Limitations}

Although the measurement, analysis, and findings went very positively to assures a result with significant. There were several limitations should be acknowledged in terms of unit of analysis - and strategies of testing the impact learning organisations on enhancing knowledge creation. One major limitation is the human limitation 
that is presented within this study. A as the study population was limited to include executive managers who work at commercial bank in Amman, Jordan only. While choosing executive managers was effective and appropriate for the current study, it would've been more effective to incorporate a bigger sample to acquire better outcomes. It would also be preferable to broaden the scope of the study to include commercial bank other than the ones in Amman, Jordan and have it from across the entire Hashemite Kingdom of Jordan. In addition, further qualitative research would be required later on to measure the role of learning organization on enhancing knowledge creation accurately. Further research into the broader and more extensive the role of learning organization on enhancing knowledge creation with any new outcomes, regardless of whether they are positive or negative, would be highly valued and appreciated by the researcher.

\section{References}

Akhavan, P., Ghojavand, S., \& Abdali, R. (2012). Knowledge sharing and its impact on knowledge creation. Journal of Information \& Knowledge Management, 11(02). https://doi.org/10.1142/S0219649212500128

Alipour, F., Idris, K., \& Karimi, R. (2011). Knowledge creation and transfer: Role of learning organization. International Journal of Business Administration, 2(3), 61. https://doi.org/10.5430/ijba.v2n3p61

Arijitsatien, C., \& Ractham, V. (2017). The Effects of Knowledge Creation Process upon the Organizational Performance: A Study of Thai Banking Industry. International Journal of Culture and History, 3(4), 236242. https://doi.org/10.18178/ijch.2017.3.4.106

Baldwin, M. (2016). Social work, critical reflection and the learning organization. Routledge.

Bratianu, C. (2015). Organizational Learning and the Learning Organization. Organizational Knowledge Dynamics: Managing Knowledge Creation, Acquisition, Sharing, and Transformation. Hershey, PA: Information Science Reference. https://doi.org/10.4018/978-1-4666-8318-1

Bryson, J. M. (2018). Strategic planning for public and nonprofit organizations: A guide to strengthening and sustaining organizational achievement. John Wiley \& Sons.

Ceptureanu. S. (2010). Knowledge Creation / Conversion Process. Review of International Comparative Management, 11(1), 150-157.

Chatterjee, A., Pereira, A., \& Sarkar, B. (2018). Learning transfer system inventory (LTSI) and knowledge creation in organizations. The Learning Organization, 25(5), 305-319. https://doi.org/10.1108/TLO-06-2016-0039

Dekoulou, P., \& Trivellas, P. (2015). Measuring the impact of learning organization on job satisfaction and individual performance in Greek advertising sector. Procedia-Social and Behavioral Sciences, 175, 367-375. https://doi.org/10.1016/j.sbspro.2015.01.1212

Donate, M. J., \& De Pablo, J. D. S. (2015). The role of knowledge-oriented leadership in knowledge management practices and innovation. Journal of Business Research, 68(2), 360-370. https://doi.org/10.1016/j.jbusres.2014.06.022

Ghaffari, S., Burgoyne, J., \& Shah, I. M. (2017). Assessing the Psychometric Properties of Dimensions of the Learning Organization Questionnaire in the Malaysian Public Higher Education Context. Australian Journal of Basic and Applied Sciences, 11(11), 1-9.

Grimsdottir, E., \& Edvardsson, I. R. (2018). Knowledge Management, Knowledge Creation, and Open Innovation in Icelandic SMEs. SAGE Open, 8(4). https://doi.org/10.1177/2158244018807320

Hajir, J., Obeidat, B., Al-dalahmeh, M., \& Masa'deh, R. (2015). The role of knowledge management infrastructure in enhancing innovation at mobile telecommunication companies in Jordan. European Journal of Social Sciences, 50(3), 313-330.

Harris, A. (2009). Distributed leadership and knowledge creation. In Distributed leadership according to the evidence (pp. 271-284). Routledge. https://doi.org/10.1007/978-1-4020-9737-9_2

Hassan, S., Iqbal, Y. M. J., \& Ghias, W. (2017). Organizational Learning and Competitive Advantage in Banking Sector of Pakistan. Global Social Sciences Review, 2(1), 79-90. https://doi.org/10.31703/gssr.2017(II-I).05

Hislop, D., Bosua, R., \& Helms, R. (2018). Knowledge management in organizations: A critical introduction. Oxford university press.

Hong, F. L. (2010). Nonaka s knowledge creation model: Universal or particularistic? University of Macau, Chinese. 
Jarvenpaa, S., \& Tanriverdi, H. (2018). How does A Firms Choice of Hierarchy Versus Platform Mode of Governance Affect Knowledge Worker Behaviors around Knowledge Creation, Profit Sharing, and Quitting? Academy of Management Global Proceedings, 26.

Kim, J., Egan, T., \& Tolson, H. (2015). Examining the dimensions of the learning organization questionnaire: A review and critique of research utilizing the DLOQ. Human Resource Development Review, 14(1), 91-112. https://doi.org/10.1177/1534484314555402

Kinyua, G. M., Muathe, S. M. A., \& Kilika, J. M. (2015). Effect of knowledge conversion and knowledge application on performance of commercial banks in Kenya. International Journal of Education and Research, 3(10), 431-445. https://doi.org/10.11648/j.sjbm.20150306.13

Laeeque, S. H., \& Babar, S. F. (2017). Knowledge Creation and Firm Performance: Is Innovation the Missing Link?. Pakistan Journal of Commerce and Social Sciences, 11(2), 505-523.

Leufvén, M., Vitrakoti, R., Bergström, A., Ashish, K. C., \& Målqvist, M. (2015). Dimensions of Learning Organizations Questionnaire (DLOQ) in a low-resource health care setting in Nepal. Health Research Policy and Systems, 13(1), 6. https://doi.org/10.1186/1478-4505-13-6

Martineau, M., Knox, K., \& Combs, P. (2014). Learning, Lending, and Laws: Banks as Learning Organizations in a Regulated Environment. American Journal of Industrial and Business Management, 4(3), 141. https://doi.org/10.4236/ajibm.2014.43021

Massaro M., Handley K., Bagnoli C., Dumay J. (2016). Knowledge management in small and medium enterprises: A structured literature review. Journal of Knowledge Management, 20, 258-291. https://doi.org/10.1108/JKM-08-2015-0320

Mbuthia, R. N. (2018). Learning Organization Dimensions And Organizational Performance Of Commercial Banks In Kenya: Survey Of Commercial Banks In Ongata Rongai Township (Doctoral Dissertation, School Of Business, Kenyatta University).

McKenzie, J., \& Varney, S. (2018). Energizing middle managers' practice in organizational learning. The Learning Organization, 25(6), 383-398. https://doi.org/10.1108/TLO-06-2018-0106

Nadayama, N. (2010). Knowledge creation in innovative projects: Comparison between the planning and implementation phases using multiple case studies. Master's thesis, Finland

Naicker, K., Govender, K. K., \& Naidoo, K. (2014). Conceptualizing knowledge creation, conversion and transfer. Trends and Development in Management Studies, 3(1), 23-58.

Nazari, K., \& Pihie, Z. A. L. (2012). Assessing learning organization dimensions and demographic factors in technical and vocational colleges in Iran. International Journal of Business and Social Science, 3(3).

Niccolini, F., Bartolacci, C., Cristalli, C., \& Isidori, D. (2018). Virtual and inter-organizational processes of knowledge creation and $\mathrm{Ba}$ for sustainable management of rivers1. Handbook of Knowledge Management for Sustainable Water Systems, 261-285. https://doi.org/10.1002/9781119271659.ch11

Örtenblad, A. (2018). What does "learning organization" mean? The Learning Organization, 25(3), 150-158. https://doi.org/10.1108/TLO-02-2018-0016

Ouma, R., \& Kombo, H. (2016). Effect of Organizational Learning on Organizational Performance of Food Manufacturing Firms in Nairobi County, Keny. European Journal of Business and Management, 8(30), 54-61.

Pei, N. S. (2008). Enhancing knowledge creation in organizations. Communications of the IBIMA, 3(2), 1-6.

Räisänen, T. (2010). All for One, One for All: Organizational knowledge creation and utilization using a new generation of IT tools. Academic Dissertation, University of Oulu, Finland.

Sánchez, J. H., Sánchez, Y. H., Collado-Ruiz, D., \& Cebrián-Tarrasón, D. (2013). Knowledge creating and sharing corporate culture framework. Procedia-Social and Behavioral Sciences, 74, 388-397. https://doi.org/10.1016/j.sbspro.2013.03.029

Sen, S., \& Paul, A. (2017). Performance Evaluation of Public And Private Sector Banks In India: A Comparative Study. Journal of Commerce, Economics \& Computer Science, 3(4), 78-82.

Serrat, O. (2008). Notions of Knowledge Management. working paper, Knowledge Solutions.

Shih, K. H., Chang, C. J., \& Lin, B. (2010). Assessing knowledge creation and intellectual capital in banking industry. Journal of intellectual capital, 11(1), 74-89. https://doi.org/10.1108/14691931011013343 
Skaik, A. A. (2017). Effect of the learning organization on organizational commitment in local commercial banks in the gaza strip. Master degree, The Islamic University-Gaza, Palestine.

Song, J. H., Joo, B. K., \& Chermack, T. J. (2009). The dimensions of learning organization questionnaire (DLOQ): A validation study in a Korean context. Human Resource Development Quarterly, 20(1), 43-64. https://doi.org/10.1002/hrdq.20007

Tai-Ning, Y., Hsiao-Chen, C., Shou-Yen, L., \& Chiao-Lun, T. (2011). Knowledge creation and intellectual capital on securities investment services. African Journal of Business Management, 5(3), 924-933.

Tan, S. C., \& Tan, Y. H. (2014). Perspectives of knowledge creation and implications for education. In Knowledge creation in education (pp. 11-34). Springer, Singapore. https://doi.org/10.1007/978-981-287-047-6_2

Vince, R. (2018). The learning organization as paradox: being for the learning organization also means being against it. The Learning Organization, 25(4), 273-280. https://doi.org/10.1108/TLO-08-2017-0083

Yang, C. W., Fang, S. C., \& Lin, J. L. (2010). Organisational knowledge creation strategies: A conceptual framework. International Journal of Information Management, 30(3), 231-238. https://doi.org/10.1016/j.ijinfomgt.2009.08.005

\section{Copyrights}

Copyright for this article is retained by the author(s), with first publication rights granted to the journal.

This is an open-access article distributed under the terms and conditions of the Creative Commons Attribution license (http://creativecommons.org/licenses/by/4.0/). 